\title{
PER2 is downregulated by the LPS-induced inflammatory response in synoviocytes in rheumatoid arthritis and is implicated in disease susceptibility
}

\author{
HWAYOUNG LEE ${ }^{1}$, SEONG-SU NAH ${ }^{2}$, SUNG-HAE CHANG ${ }^{2}$, \\ HYUNG-KI KIM $^{1}$, JUN-TACK KWON ${ }^{1}$, SANGHYUN LEE ${ }^{3}$, IK-HYUN CHO ${ }^{4}$, \\ SANG WON LEE ${ }^{5}$, YOUNG OCK KIM ${ }^{5}$, SEUNG-JAE HONG ${ }^{6}$ and HAK-JAE KIM ${ }^{1}$ \\ ${ }^{1}$ Department of Clinical Pharmacology, College of Medicine; ${ }^{2}$ Division of Rheumatology, \\ Department of Internal Medicine, College of Medicine, Soonchunhyang University, Cheonan, \\ Chungcheongnam 31151; ${ }^{3}$ Department of Integrative Plant Science, Chung-Ang University, Anseong, Gyeonggi 17546; \\ ${ }^{4}$ Department of Convergence Medical Science, Brain Korea 21 Plus Program and Institute of Korean Medicine, \\ College of Oriental Medicine, Kyung Hee University, Seoul 02453; ${ }^{5}$ Department of Development of Ginseng and \\ Medical Plants Research Institute, Rural Administration, Eumseong, Chungcheongbuk 27709; ${ }^{6}$ Division of Rheumatology, \\ Department of Internal Medicine, School of Medicine, Kyung Hee University, Seoul 02453, Republic of Korea
}

Received April 7, 2016; Accepted March 16, 2017

DOI: $10.3892 / \mathrm{mmr} .2017 .6578$

\begin{abstract}
The clinical symptoms of rheumatoid arthritis (RA) present with circadian variation, with joint stiffness and pain more prominent in the early morning. The mammalian clock genes, which include circadian locomotor output cycles kaput, brain and muscle Arnt-like protein 1, period and cryptochrome, regulate circadian rhythms. In order to identify the association between genetic polymorphisms in the circadian clock gene period 2 (PER2) and RA, the present study genotyped three PER2 single nucleotide polymorphisms (SNPs), rs934945, rs6754875, and rs2304674, using genetic information from 256 RA patients and 499 control subjects. Primary cultured rheumatoid synovial cells were stimulated with $10 \mu \mathrm{M}$ lipopolysaccharide (LPS). Total protein was then extracted from the synovial cells following 12 and $24 \mathrm{~h}$, and PER2 protein expression was assayed by immunoblotting. The rs2304674 SNP demonstrated a significant association with susceptibility to RA following Bonferroni correction. However, statistical analysis indicated that the SNPs were not associated with any clinical features of patients with RA. Immunoblotting analysis demonstrated that PER2 protein expression was decreased by LPS-induced inflammation in RA synovial cells; however, this
\end{abstract}

Correspondence to: Professor Hak-Jae Kim, Department of Clinical Pharmacology, College of Medicine, Soonchunhyang University, 319 Hyangseolwuihakgwan, 31 Soonchunhyang 6-gil, Cheonan, Chungcheongnam 31151, Republic of Korea

E-mail: hak3962@sch.ac.kr

Key words: rheumatoid arthritis, synoviocytes, polymorphism, period 2 gene, association was not observed in normal synovial cells. The results suggest that the PER2 gene may be a risk factor for RA, and expression of the PER2 protein may be affected by inflammation. Therefore, PER2 may contribute to the pathogenesis of RA.

\section{Introduction}

Rheumatoid arthritis (RA) is a chronic autoimmune disease characterized by inflammatory cell infiltration, progressive destruction of cartilage and bone, and synovial cell hyperplasia and hypertrophy (1). RA patients typically experience joint pain, stiffness and functional disability in the early morning h (2). Patients with chronic inflammatory diseases exhibit disrupted circadian rhythms $(3,4)$.

Several studies have reported a bi-directional interaction between inflammation and the circadian clock (5-7). Immune system performance is significantly affected by disruption of the circadian clock (6), and the cellular expression of core clock genes directly alters inflammation (7). This phenomenon may negatively impact the pathogenesis of RA. In addition, disturbances in the circadian clock have serious effects on a number of diseases, including immune-mediated disorders of the brain (7), infections $(8,9)$, cardiovascular disease and sleep disorders (10). The molecular mechanisms underlying circadian rhythm regulation involve an interplay between feedback and feed-forward transcriptional loops including clock genes, such as circadian locomotor output cycles kaput (CLOCK), brain and muscle ARNT like-1 (BMAL1), rar-related orphan receptor $\alpha$, deleted in esophageal cancer-1 and -2, cryptochrome $(C R Y)-1$ and -2, nuclear receptor subfamily 1 group D member 1 and period (PER)-1, -2, and -3 (11-14), which alter the expression of a number of clock-controlled genes (15).

Amongst the clock genes, period 2 (PER2) is located on the long arm of chromosome 2 at position 37.3, and encompasses 
25 exons encoding PER2 proteins, which are key molecular components in controlling mammalian circadian rhythms at the level of gene expression, physiology and pathology (16). PER2 inhibits transcriptional activation of CLOCK/BMAL1 in vitro $(17,18)$ by binding to enhancer-box motifs in their respective promoters (19). PER proteins are phosphorylated by several isoforms of casein kinase 1 in a complex manner, which regulates their degradation and nuclear trafficking (20). In addition, PER1 and PER2 form stable complexes with the casein kinases and either of the CRY proteins (17,21). PER proteins are the rate-limiting component for this step, and are necessary for nuclear import of the complex; they serve as shuttles for nuclear CRY proteins (22). Nuclear CRY and PER proteins inhibit the activity of the heterodimeric BMAL1-CLOCK complex (BCC), potentially via different mechanisms (17), thereby terminating four negative feedback loops and regulating the expression of $C R Y$ and $P E R$ genes. $P E R 2$ serves a role in the positive regulation of aryl hydrocarbon receptor nuclear translocator like (ARNTL, also known as BMAL1) expression (23). In humans, a single mutation in PER2 causes familial advanced sleep phase syndrome (24), and its loss causes arhythmicity in mice $(25,26)$. The behavioral phenotypes of Perl-null mutant mice are similar to those of Per 2 mutants; however, comparison of the molecular consequences of these mutations revealed significant differences between the two. Disruption of Per2 expression was reported to result in reduced transcription levels of further clock genes, whereas Perl appeared to function predominantly at the posttranscriptional level (26).

Previous studies have suggested that the circadian rhythm is associated with cortisol levels; cortisol levels are highest in the early morning immediately after awakening, whereas they are low at around midnight $(27,28)$. In addition, the circadian clock gene PER2, which is generated in the suprachiasmatic nucleus of the hypothalamus (29), is associated with the hypothalamic-pituitary-adrenal axis, stress (30), and neuroendocrine-immunologic pathways, which are relevant to rheumatic diseases $(30,31)$. Based on these observations, the present study aimed to investigate the association between polymorphisms in the PER2 gene in Korean RA patients, and to determine the expression levels of PER2 in synovial RA cells during lipopolysaccharide (LPS)-induced inflammation.

\section{Materials and methods}

Subjects. A case-control study was conducted to determine the genetic association between PER2 single nucleotide polymorphisms (SNPs) and RA. A total of 256 unrelated patients with RA (age, 50.47 \pm 12.85 years; male/female, 47/209) were enrolled between January and February 2008 from the rheumatic center of Kyung Hee University Hospital (Seoul, Korea). Each patient was diagnosed by a rheumatologist according to ACR 1987 Rheumatoid Arthritis diagnostic criteria (32). A total of 499 control subjects (age, $46.05 \pm 12.67$; male/female, $215 / 284$ ) that participated in a general health checkup program of Kyung Hee University Hospital were recruited. Patients with diabetes (fasting blood sugar $>120 \mathrm{mg}$ ), hypertension (systolic blood pressure $>140 \mathrm{~mm} \mathrm{Hg}$ and/or diastolic blood pressure $>90 \mathrm{~mm} \mathrm{Hg}$ ), dyslipidemia (total cholesterol $>200 \mathrm{mg} / \mathrm{dl}$ and triglyceride levels $>150 \mathrm{mg} / \mathrm{dl}$ ), obesity (body mass index $\left.(\mathrm{BMI})>30 \mathrm{~kg} / \mathrm{m}^{2}\right)$, smoking or previous history of smoking 5 years ago, postmenopausal women, evidence of cardio vascular disease or family history of coronary heart disease were excluded from the present study. This study was performed in accordance with the guidelines set forth by the Declaration of Helsinki, and written informed consent was obtained from all subjects. This study was approved by the ethics review committee of the Medical Research Institute, School of Medicine, Kyung Hee University. Demographic data were obtained from patient medical records or through interviews at the time of enrollment. Disease activity was determined on the basis of the following biochemical parameters: C-reactive protein (CRP), erythrocyte sedimentation rate (ESR) and titer of rheumatoid factor (RF). X-rays of the hands and feet were obtained from all patients and radiographic findings were used to classify patients with bone erosion.

Human cartilage samples were obtained from 3 female healthy individuals (age, 42.33 \pm 12.06 years; weight, $65.00 \pm 12.53 \mathrm{~kg}$ ), 3 female patients with osteoarthritis (OA; age, $52.67 \pm 7.51$ years; weight, $68.33 \pm 6.43 \mathrm{~kg}$ ) and 3 female patients with RA (age, 49.66 \pm 7.64 years; weight, $60.00 \pm 9.85 \mathrm{~kg}$ ) at the Soonchunhyang University Hospital (Cheonan, Korea) between December 2011 and November 2012. The study protocol was approved by the Institutional Review Board of the Soonchunhyang University College of Medicine. Written informed consent was obtained from all subjects prior to enrollment.

SNP genotyping. PER2 SNPs were identified using National Center for Biotechnology Information websites (www. ensembl.org; www.ncbi.nlm.nih.gov/SNP; and www.hapmap. org). A total of 3 PER2 SNPs were selected for analysis, as previously described $(33,34)$. The three selected SNPs consisted of one nonsynonymous SNP (rs934945) and two intronic SNPs (rs2304674 and rs6754875). Blood samples were drawn from all subjects following overnight fasting. DNA was isolated from whole blood samples of each subject using the GenEx ${ }^{\mathrm{TM}}$ Blood kit (cat. no. 220-301; GeneAll Biotechnology, Co., Ltd., Seoul, Korea), according to the manufacturer's instructions. PER2 SNPs were genotyped according to a previously described method (35). Genomic DNA was amplified by polymerase chain reaction (PCR) using primers for each SNP. Oligonucleotide primers of PER2 were the following: rs934945, sense 5'-GACTTCTGGGAGCACTG GG-3', antisense 3'-CGTGTTAGCCAGGAAGGTCT-5'; rs6754875, sense 5'-TTGTCATGGCAGCTGTCTCT-3', antisense 3'-TAGGGGAGAAAACCAGGAGA-5'; and rs2304674, sense 5'-TTGTCATGGCAGCTGTCTCT-3' and antisense 3'-TAGGGGAGAAAACCAGGAGA-5'. The PCR products were sequenced using an ABI PRISM 3730x1 DNA analyzer (Applied Biosystems; Thermo Fisher Scientific, Inc., Waltham, MA, USA). The sequence data were analyzed using SeqManII software version 6.1 (DNASTAR, Inc., Madison, WI, USA).

Cell culture and treatment. Human articular cartilage was sliced and washed in serum-free Dulbecco's modified Eagle's medium (DMEM; WELGENE, Inc., Gyeongsan, Korea) containing D-glucose, L-glutamine, sodium pyruvate and sodium bicarbonate, prior to digestion with $0.1 \%$ collagenase 
(Invitrogen; Thermo Fisher Scientific, Inc.) for $3 \mathrm{~h}$ at $37^{\circ} \mathrm{C}$. Undigested fragments were removed by filtration of the solution through a nylon mesh (70 $\mu \mathrm{m}$ mesh size; BD Biosciences, Franklin Lakes, NJ, USA). Isolated cells were washed three times with PBS ( $\mathrm{pH}$ 7.4), centrifuged at $211 \mathrm{x}$ g for $10 \mathrm{~min}$ at room temperature and then resuspended in serum-free DMEM (WELGENE, Inc.). Subsequently, cells were incubated in DMEM supplemented with $20 \%$ fetal bovine serum (FBS; WELGENE, Inc.) and containing D-glucose, L-glutamine, sodium pyruvate, sodium bicarbonate, $100 \mathrm{U} / \mathrm{ml}$ penicillin and $100 \mu \mathrm{g} / \mathrm{ml}$ streptomycin (WELGENE, Inc.) for 4 days at $37^{\circ} \mathrm{C}$ in a $5 \% \mathrm{CO}_{2}$ atmosphere, until they reached $70-80 \%$ confluency. The morphological features and the expression levels of type II collagen and aggrecan were consistent with a chondrocytic phenotype. The cells were passaged upon reaching confluence by gentle trypsinization; cells were used for experiments between passage 4 and 8. Following stimulation with LPS (10 $\mu \mathrm{M}$; Sigma-Aldrich; Merck KGaA, Darmstadt, Germany), the cells were collected at 12 and $24 \mathrm{~h}$.

Western blot analysis. RA and normal synovial cells were cultured in $10-\mathrm{cm}$ culture dishes to $\sim 80 \%$ confluence $\left(1 \times 10^{6}\right.$ cells/well $)$ and were serum-starved in DMEM without FBS for $24 \mathrm{~h}$. The cells were subsequently incubated for a further 12 or $24 \mathrm{~h}$ in the presence of LPS. Cells were lysed in NP40 buffer (ELPIS-Biotech, Inc., Daejeon, Korea) containing $1 \mathrm{mM}$ PMSF protease inhibitor. Protein concentration was measured using a colorimetric Bio-Rad Protein assay kit (Bio-Rad Laboratories, Inc., Hercules, CA, USA). Equal amounts of protein $(50 \mu \mathrm{g})$ were separated by $12 \%$ SDS-PAGE, and transferred onto polyvinylidene difluoride membranes (EMD Millipore, Billerica, MA, USA). Following blocking with 5\% skimmed milk, membranes were probed with anti-PER2 (dilution, 1:1,000; cat. no. ab64460; Abcam, Cambridge, UK) or anti- $\beta$-actin (dilution, 1:1,000; cat. no. sc-81178; Santa Cruz Biotechnology, Inc., Dallas, TX, USA) antibodies overnight at $4^{\circ} \mathrm{C}$. Subsequently, the membrane was washed in TBS containing $0.1 \%$ Tween-20, and incubated with the following horseradish peroxidase-conjugated secondary antibodies for $1 \mathrm{~h}$ at room temperature: Anti-mouse immunoglobulin (Ig) G (dilution 1:10,000; cat. no. A9044; Sigma-Aldrich; Merck KGaA) or anti-rabbit IgG (dilution, 1:2,000; cat. no. sc-2004; Santa Cruz Biotechnology, Inc.). Protein bands were visualized using the WesternBright ${ }^{\text {TM }}$ enhanced chemiluminescence kit (Advansta, Inc., Menlo Park, CA, USA). The images were captured using the ChemiDoc ${ }^{\mathrm{TM}}$ XRS+imaging system (Bio-Rad Laboratories, Inc.). Protein bands were quantified using ImageJ image analysis software version, 1.40 (National Institutes of Health, Bethesda, MD, USA). Experiments were performed in triplicate.

Statistical analysis. The Hardy-Weinberg equilibrium (HWE) was assessed using SNPStats (https://www.snpstats. net/snpstats/start.htm?q=snpstats/start.htm). SNPStats and SNPAnalyzer Pro version 1.0 (Istech Corp., Goyang, Korea) were also used to evaluate the odds ratios (ORs), 95\% confidence intervals (CIs), and P-values. Multiple logistic regression analysis, adjusted for age and gender as covariables, was performed. In the logistic regression analysis for each SNP, models were used that assumed the following: Co-dominant
Table I. Clinical and demographic features of the RA and control subjects.

\begin{tabular}{lc}
\hline Characteristic & No. of patients \\
\hline RA subjects & 256 \\
Age $($ years, mean $\pm \mathrm{SD})$ & $50.47 \pm 12.85$ \\
Gender $($ male/female $)$ & $47 / 209$ \\
ESR $(\mathrm{mm} / \mathrm{h}$, mean $\pm \mathrm{SD})$ & $42.98 \pm 29.19$ \\
$\mathrm{ESR}(\geq 30 /<30 \mathrm{~mm} / \mathrm{h})$ & $160 / 96$ \\
$\mathrm{CRP}(\mathrm{mg} / \mathrm{dl}, \mathrm{mean} \pm \mathrm{SD})$ & $2.41 \pm 5.21$ \\
$\mathrm{CRP}(\geq 0.5 /<0.5 \mathrm{mg} / \mathrm{dl})$ & $182 / 74$ \\
$\mathrm{RF}($ positive $/$ negative $)$ & $219 / 37$ \\
Bone erosion $($ positive/negative $)$ & $134 / 122$ \\
Control subjects & 499 \\
Age $($ years, mean $\pm \mathrm{SD})$ & $46.05 \pm 12.67$ \\
Gender (male/female) & $215 / 284$ \\
\hline
\end{tabular}

RA patients that did not meet the inclusion criteria were excluded. RA, rheumatoid arthritis; SD, standard deviation; ESR, erythrocyte sedimentation rate; CRP, C-reactive protein; RF, rheumatoid factor; $\mathrm{SD}$, standard deviation.

inheritance, in which the relative hazard differs between subjects with 1 minor allele and those with 2 minor alleles; dominant inheritance, in which subjects with 1 or 2 minor alleles have the same relative hazard; or recessive inheritance, in which subjects with 2 minor alleles are at increased risk for the disease. Bonferroni correction $\left(\mathrm{P}^{\mathrm{c}}\right)$ was applied by multiplying the P-values by the number of SNPs $(\mathrm{n}=3)$. The $\chi^{2}$ test was used to compare allele frequencies between groups. To avoid coincidental findings due to multiple testing, a Bonferroni correction was applied by decreasing the significance level to $\mathrm{P}=0.01(\mathrm{P}=0.05 / 5)$ for each of the three SNPs. Western blotting results are presented as the mean \pm standard deviation and/or standard error of the mean. Differences between groups were compared using the Student's t-test. Statistical analysis of western blotting results was performed using IBM SPSS software version, 19.0 (IBM SPSS, Armonk, NY USA). P<0.05 was considered to indicate a statistically significant difference.

\section{Results}

Subject characteristics. The clinical and demographic characteristics of the RA patients and control subjects are presented in Table I. The mean age ( \pm standard deviation) of the RA patients and the control subjects was $50.47 \pm 12.85$ and $46.05 \pm 12.67$ years, respectively. There were 47 male and 209 female $(n=256)$ RA patients and 215 male and 284 female $(n=499)$ control subjects. RA patients were classified into clinical subgroups according to ESR level ( $\geq 30$ or $<30 \mathrm{~mm} / \mathrm{h}$ ), CRP level $(\geq 0.5$ or $<0.5 \mathrm{mg} / \mathrm{dl}$ ), and the presence or absence of RF and bone erosion. A total of $160 \mathrm{RA}$ patients (62.5\%) presented with ESR levels of $\geq 30 \mathrm{~mm} / \mathrm{h}$ and 96 (37.5\%) with an ESR level of $<30 \mathrm{~mm} / \mathrm{h}$. A total of 182 patients with RA (71.09\%) exhibited CRP levels of $\geq 0.5 \mathrm{mg} / \mathrm{dl}$ and 74 (28.91\%) patients displayed a CRP level of $<0.5 \mathrm{mg} / \mathrm{dl}$. There were 
219 RA patients $(85.54 \%)$ with and 37 (14.46\%) without RF. Bone erosion was present in 134 (52.34\%) and absent in 122 (47.66\%) RA patients.

SNP genotype distributions. The genotype distributions of all SNPs were in HWE (P>0.05). As shown in Table II, out of the 3 SNPs, rs2304674 alone was statistically associated with RA in the codominant $[\mathrm{OR}=0.68(0.47), 95 \% \mathrm{CI}$ : $\left.0.48-0.96(0.25-0.87), \mathrm{P}=0.0089, \mathrm{P}^{\mathrm{c}}=0.0267\right]$ and dominant model $\left(\mathrm{OR}=0.63,95 \%\right.$ CI: $\left.0.46-0.87, \mathrm{P}=0.0044, \mathrm{P}^{\mathrm{c}}=0.0132\right)$ after Bonferroni correction. In the codominant model, the respective TT and CC genotype frequencies were 55.3 and $10.1 \%$ in the control group and 66.1 and $5.7 \%$ in the RA group (Table III). The CC genotype was associated with a decreased risk of RA (Table II). In the dominant model, genotypes containing the $\mathrm{C}$ allele $(\mathrm{CC} / \mathrm{TC})$ and not containing the $\mathrm{C}$ allele (TT) made up 44.7 and $55.3 \%$ in the control group, and 33.9 and $66.1 \%$ in the RA group, respectively (Table III). The rs2304674 allele was significantly associated with RA (OR=2.02,95\% CI: 1.55-2.63, $\mathrm{P}<0.001, \mathrm{P}^{\mathrm{c}}<0.001$; Table II). The rs2304674 T allele frequency was higher in the RA $(80.2 \%)$ when compared with the control group (66.8\%; Table III). The frequency of the rs6754875 allele was loosely associated with the development of RA. The C allele of rs6754875 was less prevalent in the RA group (24.8\%) than in the control group (30.1\%; Table III); however, the difference was not significant following Bonferroni correction (Table II). The association between the 3 SNPs and the clinical characteristics of the RA patients was then assessed and included ESR, CRP, RF and bone erosion parameters. However, no significant differences were observed in these factors among the subgroups (data not shown).

Expression of PER2 in RA synovial cells during LPS-induced inflammatory response. The protein expression levels of PER2 in normal and RA synovial cells were examined by western blot analysis. The results demonstrated that the expression levels of PER2 were not significantly altered in RA synovial cells when compared with control cells under normal physiological conditions (Fig. 1). By contrast, the expression of PER2 was significantly decreased in RA synoviocytes following LPS stimulation for $24 \mathrm{~h}$, whereas normal synovial cells were unaffected (Fig. 1). The protein levels of PER2 decreased in a time-dependent manner in RA synovial cells (Fig. 2).

\section{Discussion}

The purpose of the present study was to evaluate the association between genetic polymorphisms in PER2 and susceptibility to RA, and to compare the protein expression levels of PER2 in normal and RA synoviocytes. An association between specific SNPs of the PER2 gene and RA was observed; the rs 2304674 SNP of the PER2 gene was associated with RA, with the CC genotype associated with a decreased risk of RA. In addition, immunoblotting was performed to assess PER2 expression in RA synovial cells compared with normal cells. The results revealed that PER2 expression decreased following LPS treatment for 12 and $24 \mathrm{~h}$ in RA cells, whereas no significant effect of LPS treatment on PER2 expression in control cells was observed.
Table II. Genetic models of three SNPs associated with RA.

A, rs934945 (AA, AG and GG alleles)

\begin{tabular}{lccc}
\hline Model & OR $(95 \% \mathrm{CI})$ & P-value & $\mathrm{P}^{\mathrm{c}}$-value \\
\hline Co-dominant & 1 & 0.17 & 0.51 \\
& $1.18(0.85-1.64)$ & & \\
& $1.57(0.98-2.52)$ & & \\
Dominant & $1.26(0.93-1.72)$ & 0.14 & 0.42 \\
Recessive & $1.45(0.93-2.26)$ & 0.11 & 0.33 \\
Overdominant & $1.06(0.78-1.45)$ & 0.69 & 1 \\
A or G alleles & $0.80(0.64-1.00)$ & 0.05 & 0.16 \\
\hline
\end{tabular}

B, rs6754875 (AA, AC and CC alleles)

\begin{tabular}{lccc}
\hline Model & OR $(95 \% \mathrm{CI})$ & P-value & $\mathrm{P}^{\mathrm{c}}$-value \\
\hline Co-dominant & 1 & 0.09 & 0.26 \\
& $0.71(0.51-0.99)$ & & \\
& $0.69(0.40-1.20)$ & & \\
Dominant & $0.70(0.52-0.96)$ & 0.03 & 0.08 \\
Recessive & $0.79(0.46-1.35)$ & 0.39 & 1 \\
Overdominant & $0.75(0.62-0.99)$ & 0.04 & 0.12 \\
A or C alleles & $1.31(1.02-1.67)$ & 0.03 & 0.10 \\
\hline
\end{tabular}

C, rs2304674 (TT, TC and CC alleles)

\begin{tabular}{lccc}
\hline Model & OR $(95 \% \mathrm{CI})$ & P-value & $\mathrm{P}^{\mathrm{c}}$-value \\
\hline Co-dominant & 1 & 0.01 & 0.03 \\
& $0.68(0.48-0.96)$ & & \\
& $0.47(0.25-0.87)$ & & \\
Dominant & $0.63(0.46-0.87)$ & 0.004 & 0.01 \\
Recessive & $0.53(0.29-0.98)$ & 0.04 & 0.11 \\
Overdominant & $0.74(0.53-1.04)$ & 0.08 & 0.23 \\
T or C alleles & $2.02(1.55-2.63)$ & $<0.001$ & $<0.001$ \\
\hline
\end{tabular}

OR, odds ratio; $\mathrm{CI}$, confidence intervals; $\mathrm{P}^{\mathrm{c}}$-value, $\mathrm{P}$-value corrected using Bonferroni's method.

Previous studies have demonstrated that LPS modifies the biological clock $(5,6)$ via alterations in the expression of several circadian clock genes, including Per2 (36). It has been suggested that LPS impacts on the timing of the circadian rhythm by altering the levels of proinflammatory cytokines in the brain (36), and thus affects rheumatic diseases (37). Immune signaling molecules affect circadian rhythms; however, the circadian system in turn regulates the immune system. A number of immune markers have been implicated in circadian regulation, including interleukin (IL)-2, IL-10, granulocyte-macrophage colony stimulating factor, $\mathrm{C}-\mathrm{C}$ motif chemokine receptor 2 , IL-6, IL-1 $\beta$, tumor necrosis factor (TNF)- $\alpha$, monocyte chemotacticprotein-1, interferon (IFN)- $\gamma$ and IFN receptors $(38,39)$. In addition, genetic manipulations of circadian timing modulate innate immunity. A previous 
Table III. Genotype and allele frequencies of PER2 SNPs identified in RA and control subjects.

A, rs934945

Genotype/allele Control frequency (\%) RA frequency (\%)

\begin{tabular}{lrr}
\hline AA & $55(11.1)$ & $38(15.3)$ \\
AG & $206(41.6)$ & $107(43.1)$ \\
GG & $234(47.3)$ & $103(41.5)$ \\
Total A & $316(31.9)$ & $184(36.9)$ \\
Total G & $674(68.1)$ & $314(63.1)$ \\
\hline
\end{tabular}

B, rs6754875

Genotype/allele Control frequency (\%) RA frequency (\%)

\begin{tabular}{lrc}
\hline AA & $235(50.2)$ & $146(58.9)$ \\
AC & $184(39.3)$ & $81(32.7)$ \\
CC & $49(10.5)$ & $21(8.5)$ \\
Total A & $654(69.9)$ & $373(75.2)$ \\
Total C & $282(30.1)$ & $123(24.8)$ \\
\hline
\end{tabular}

C, rs 2304674

Genotype/allele Control frequency (\%) RA frequency (\%)

\begin{tabular}{lcc}
\hline TT & $268(55.3)$ & $164(66.1)$ \\
TC & $168(34.6)$ & $70(28.2)$ \\
CC & $49(10.1)$ & $14(5.7)$ \\
Total T & $536(66.8)$ & $398(80.2)$ \\
Total C & $266(33.2)$ & $98(19.8)$ \\
\hline
\end{tabular}

Unclear or missing genotype data were excluded; therefore, the total numbers of genotypes and alleles in each SNP are different. PER2, period 2 gene; SNP, single nucleotide polymorphism; RA, rheumatoid arthritis.

study demonstrated that the daily rhythm of IFN- $\gamma$ mRNA and protein expression was absent in Per2-mutant mice (40). Furthermore, these mice were deficient in their ability to produce IL-10 and IFN- $\gamma$ in response to LPS (41). Notably, macrophages display endogenous rhythms in clock gene expression $(39,42)$, phagocytosis (43) and LPS sensitivity (44).

In a previous study, Hashiramoto et al (43) investigated the association between mammalian clock genes and arthritis using knockout animals and collagen-induced arthritis animal models. The authors examined whether the daily expression of clock genes in the synovial cells of foot joints was altered by the induction of arthritis using a mixture of anti-type II collagen monoclonal antibodies and LPS. In naive C57/BL6 mouse joints, daily expression of nuclear PER2 was lower during the daylight (8:00 a.m.) and higher at night (8:00 p.m.), whereas in arthritic joints, PER2 was expressed even during daylight (8:00 a.m.). Induction of arthritis resulted in a $6 \mathrm{~h}$ retrograde shift in Perl/2 mRNA expression. The authors suggested that normal circadian gene expression profiles

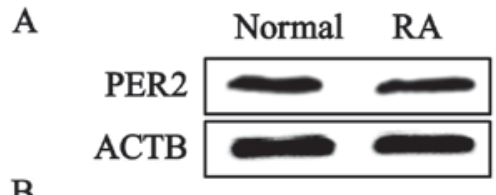

B

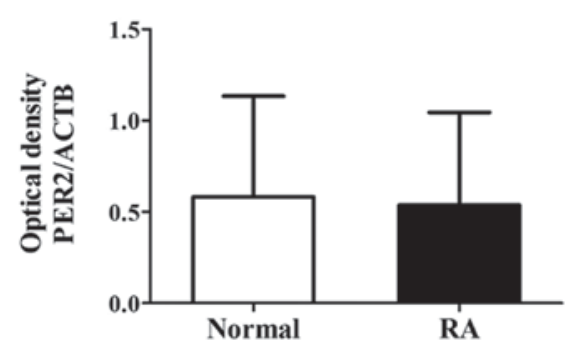

Figure 1. Western blot analysis of PER2 protein expression. (A) PER2 expression levels in control and RA cells was determined by immunoblotting $(n=3)$. ACTB served as an internal control. (B) Ratio of PER2 to ACTB protein expression as determined by Image J software (version, 1.40). Data are presented as the mean \pm standard deviation. Normal, normal synovial cells; RA, rheumatoid arthritis synovial cells; PER2, period 2; ACTB, $\beta$-actin.
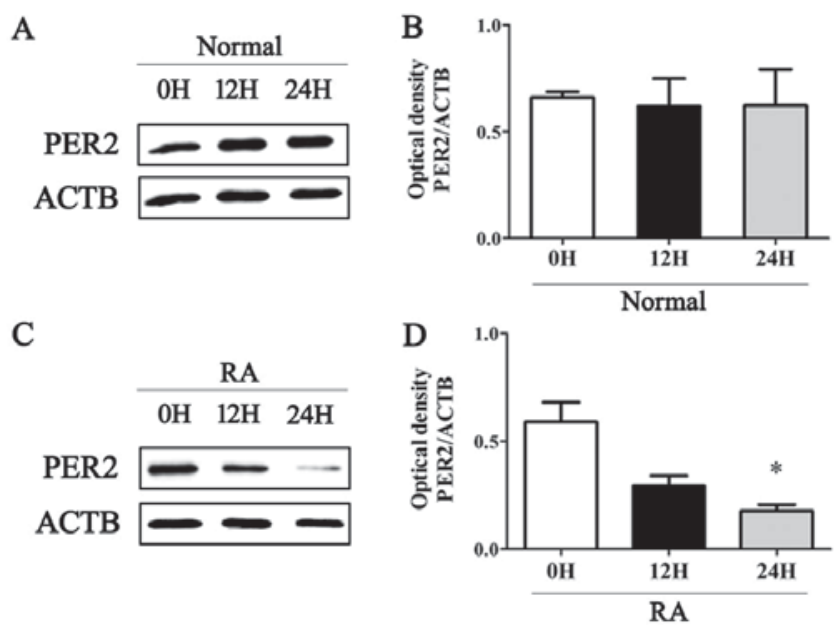

Figure 2. Expression of PER2 during the LPS-induced inflammatory response in control and RA synovial cells. (A) Western blot analysis and (B) quantification of band densities of PER2 protein expression in normal synovial cells $(\mathrm{n}=3)$. Normal cells were serum-starved for $24 \mathrm{~h}$ and subsequently treated with $10 \mu \mathrm{M}$ LPS for 0,12 or $24 \mathrm{~h}$. ACTB served as an internal control. (C) Western blot analysis and (D) quantification of band densities of PER2 protein expression in RA synovial cells $(n=3)$. RA cells were serum-starved for $24 \mathrm{~h}$ and subsequently treated with $10 \mu \mathrm{M}$ LPS for 0,12 or $24 \mathrm{~h}$. The ratio of PER2 to ACTB expression was determined using ImageJ software (version, 1.40). Data are presented as the mean \pm standard deviation. ${ }^{*} \mathrm{P}<0.05$ vs. $0 \mathrm{~h}$ treatment. LPS, lipopolysaccharide; normal, normal synovial cells; RA, rheumatoid arthritis synovial cells; PER2, period 2; ACTB, $\beta$-actin.

are significantly disturbed in arthritic conditions (43). In the study, an influence of arthritis on clock gene expression was reported in wild-type mice that were administered with an anti-collagen antibody and LPS, following the assessment of PER2 protein levels in the synovium (42). They found that PER2 is usually expressed at night; however, in the arthritis model PER2 was highly expressed in the morning. In addition, the phase of Perl and Per2 mRNA expression in spleen lymphocytes was shifted back $\sim 6 \mathrm{~h}$, and overall Bmall, Perl, and Per 2 mRNA expression levels were reduced. Furthermore, the authors observed that TNF- $\alpha$ inhibited the expression of 
PER2 in RA fibroblast-like synoviocytes, and it was suggested that the onset of arthritis may impact on the expression of clock genes in vivo (44). Decreased expression of PER2 by TNF- $\alpha$ may additionally contribute to the resistance of synovial cells to apoptosis, and may contribute to tumor-like growth of the synovium. In agreement with previous studies, the expression of PER2 observed in the present study was similar between control and RA synoviocytes under normal conditions; however, expression was decreased in RA synoviocytes following induction of the inflammatory response.

The present study was the first to investigate the potential effect of PER2 SNPs and PER2 expression in RA. The results indicate that $P E R 2$ polymorphisms may contribute to increased RA susceptibility via alterations in PER2 protein expression. PER 2 may be one of several genes that serve a role in polygenic susceptibility to RA. Due to the relatively small number of subjects in the current study, these findings must be validated by future studies using larger sample sizes. In addition, a substantial difference was present in the sex ratio of the study population. Sex and age were adjusted for during all statistical analyses; however, this inconsistency is a limitation of the current study and further validation is required. Future investigations should employ in vitro or animal models to further elucidate the role of PER2 in RA.

\section{Acknowledgements}

The present study was supported by the Cooperative Research Program for Agriculture Science and Technology Development (project no. PJ011582) of the Rural Development Administration of Korea.

\section{References}

1. Lee DM and Weinblatt ME: Rheumatoid arthritis. Lancet 358: 903-911, 2001.

2. Haas S and Straub RH: Disruption of rhythms of molecular clocks in primary synovial fibroblasts of patients with osteoarthritis and rheumatoid arthritis, role of IL-1 $\beta / T N F$. Arthritis Res Ther 14: R122, 2012.

3. Straub RH and Cutolo M: Circadian rhythms in rheumatoid arthritis: Implications for pathophysiology and therapeutic management. Arthritis Rheum 56: 399-408, 2007.

4. Gibbs JE and Ray DW: The role of the circadian clock in rheumatoid arthritis. Arthritis Res Ther 15: 205, 2013.

5. Keller M, Mazuch J, Abraham U, Eom GD, Herzog ED, Volk HD, Kramer A and Maier B: A circadian clock in macrophages controls inflammatory immune responses. Proc Natl Acad Sci USA 106: 21407-21412, 2009.

6. Castanon-Cervantes O, Wu M, Ehlen JC, Paul K, Gamble KL, Johnson RL, Besing RC, Menaker M, Gewirtz AT and Davidson AJ: Dysregulation of inflammatory responses by chronic circadian disruption. J Immunol 185: 5796-5805, 2010.

7. Coogan AN and Wyse CA: Neuroimmunology of the circadian clock. Brain Res 1232: 104-112, 2008.

8. Segall LA, Perrin JS, Walker CD, Stewart J and Amir S: Glucocorticoid rhythms control the rhythm of expression of the clock protein, Period2, in oval nucleus of the bed nucleus of the stria terminalis and central nucleus of the amygdala in rats. Neuroscience 140: 753-757, 2006.

9. Burioka N, Fukuoka Y, Takata M, Endo M, Miyata M, Chikumi H, Tomita K, Kodani M, Touge H, Takeda K, et al: Circadian rhythms in the CNS and peripheral clock disorders: Function of clock genes: Influence of medication for bronchia asthma on circadian gene. J Pharmacol Sci 103: 144-149, 2007.

10. Young ME: The circadian clock within the heart: Potential influence on myocardial gene expression, metabolism, and function. Am J Physiol Heart Circ Physiol 290: H1-H16, 2006.
11. Reppert SM and Weaver DR: Coordination of circadian timing in mammals. Nature 418: 935-941, 2002.

12. Roenneberg $\mathrm{T}$ and Merrow $\mathrm{M}$ : The network of time: Understanding the molecular circadian system. Curr Biol 13: R198-R207, 2003.

13. Dunlap JC: Molecular bases for circadian clocks. Cell 96: 271-290, 1999.

14. Young MW and Kay SA: Time zones: A comparative genetics of circadian clocks. Nat Rev Genet 2: 702-715, 2001.

15. Yamamoto T, Nakahata Y, Soma H, Akashi M, Mamine T and Takumi T: Transcriptional oscillation of canonical clock genes in mouse peripheral tissues. BMC Mol Biol 5: 18, 2004.

16. Vukolic A, Antic V, Van Vliet BN, Yang Z, Albrecht U and Montani JP: Role of mutation of the circadian clock gene PER2 in cardiovascular circadian rhythms. Am J Physiol Regul Integr Comp Physiol 298: R627-R634, 2010.

17. Akashi M, Tsuchiya Y, Yoshino T and Nishida E: Control of intracellular dynamics of mammalian period proteins by casein kinase I epsilon (CKIepsilon) and CKIdelta in cultured cells. Mol Cell Biol 22: 1693-1703, 2002.

18. Jin X, Shearman LP, Weaver DR, Zylka MJ, de Vries GJ and Reppert SM: A molecular mechanism regulating rhythmic output from the suprachiasmatic circadian clock. Cell 96: 57-68, 1999.

19. Cavadini G, Petrzilka S, Kohler P, Jud C, Tobler I, Birchler T and Fontana A: TNF-alpha suppresses the expression of clock genes by interfering with E-box-mediated transcription. Proc Natl Acad Sci USA 104: 12843-12848, 2007.

20. Vanselow K, Vanselow JT, Westermark PO, Reischl S, Maier B, Korte T, Herrmann A, Herzel H, Schlosser A and Kramer A: Differential effects of PER2 phosphorylation: Molecular basis for the human familial advanced sleep phase syndrome (FASPS). Genes 20: 2660-2672, 2006.

21. Dunlap JC, Loros JJ and DeCoursey PT: Biological timekeeping 1st edition. Sunderland (Massachusetts): Sinauer Associates, Chronobiology, 406, 2004.

22. Lee C, Etchegaray JP, Cagapang FR, Loudon AS and Reppert SM: Posttranslational mechanisms regulate the mammalian circadian clock. Cell 107: 855-867, 2001.

23. Reppert SM and Weaver DR: Molecular analysis of mammalian circadian rhythms. Annu Rev Physiol 63: 647-676, 2001.

24. Toh KL, Jones CR, He Y, Eide EJ, Hinz WA, Virshup DM,Ptácek LJ and $\mathrm{Fu} \mathrm{YH}: \mathrm{An}$ hPer2 phosphorylation site mutation in familial advanced sleep phase syndrome. Science 291: 1040-1043, 2001.

25. Zheng B, Larkin DW, Albrecht U, Sun ZS, Sage M, Eichele G, Lee CC and Bradley A: The mPer2 gene encodes a functional component of the mammalian circadian clock. Nature 400: 169-173, 1999.

26. Bae K, Jin X, Maywood ES, Hastings MH, Reppert SM and Weaver DR: Differential functions of mPer1, mPer2, and mPer3 in the SCN circadian clock. Neuron 30: 525-536, 2001.

27. Mottonen T, Hannonen P, Leirisalo-Repo M, Nissilä M, Kautiainen H, Korpela M, Laasonen L, Julkunen H, Luukkainen R, Vuori K, et al: Comparison of combination therapy with single-drug therapy in early rheumatoid arthritis: A randomised trial. FIN-RACo trial group. Lancet 353: 1568-1573, 1999.

28. Moreland LW, Baumgartner SW, Schiff MH, Tindall EA, Fleischmann RM, Weaver AL, Ettlinger RE, Cohen S, Koopman WJ, Mohler K, et al: Treatment of rheumatoid arthritis with a recombinant human tumor necrosis factor receptor (p75)-Fc fusion protein. N Engl J Med 337: 141-147, 1997.

29. Nader N, Chrousos GP and Kino T: Interactions of the circadian CLOCK system and the HPA axis. Trends Endocrinol Metab 21: 277-286, 2010

30. Kowanko IC, Knapp MS, Pownall R and Swannell AJ: Domiciliary self-measurement in the rheumatoid arthritis and the demonstration of circadian rhythmicity. Ann Rheum Dis 41: 453-455, 1982.

31. Cutolo $M$ and Straub RH: Circadian rhythms in arthritis: Hormonal effects on the immune/inflammatory reaction. Autoimmu Rev 7: 223-228, 2008.

32. Arnett FC, Edworthy SM, Bloch DA, McShane DJ, Fries JF, Cooper NS, Healey LA, Kaplan SR, Liang MH, Luthra HS, et al: The American Rheumatism Association 1987 revised criteria for the classification of rheumatoid arthritis. Arthritis Rheum 31: 315-324, 1988.

33. Forbes EE, Dahl RE, Almeida JR, Ferrell RE, Nimgaonkar VL, Mansour H, Sciarrillo SR, Holm SM, Rodriguez EE and Phillips ML: PER2 rs2304672 polymorphism moderates circadian-relevant reward circuitry activity in adolescents. Biol Psychiatry 71: 451-457, 2012. 
34. Lee HJ, Kim L, Kang SG, Yoon HK, Choi JE, Park YM, Kim SJ and Kripke DF: PER2 variation is associated with diurnal preference in a Korean young population. Behav Genet 41: 273-277, 2011.

35. Kim HK, Lee WY, Kwon JT, Sohn DR, Hong SJ and Kim HJ: Association of ultraviolet radiation resistance-associated gene polymorphisms with rheumatoid arthritis. Biomed Rep 2 117-121, 2013

36. Kwak Y, Lundkvist GB, Brask J, Davidson A, Menaker M, Kristensson $\mathrm{K}$ and Block GD: Interferon-gamma alters electrical activity and clock gene expression in suprachiasmatic nucleus neurons. J Biol Rhythms 23: 150-159, 2008.

37. Davis MC, Zautra AJ, Younger J, Motivala SJ, Attrep J and Irwin MR: Chronic stress and regulation of cellular markers of inflammation in rheumatoid arthritis: Implications for fatigue. Brain Behav Immun 22: 24-32, 2008.

38. Takane H, Ohdo S, Baba R, Koyanagi S, Yukawa E and Higuchi S: Relationship between 24-hour rhythm in antiviral effect of interferon-beta and interferon-alpha/beta receptor expression in mice. Jpn J Pharmacol 90: 304-312, 2002.

39. Hayashi M, Shimba S and Tezuka M: Characterization of the molecular clock in mouse peritoneal macrophages. Biol Pharm Bull 30: 621-626, 2007.
40. Arjona A and Sarkar DK: The circadian gene mPer2 regulates the daily rhythm of IFN-gamma. J Interferon Cytokine Res 26: 645-649, 2006

41. Liu J, Malkani G, Shi X, Meyer M, Cunningham-Runddles S, Ma X and Sun ZS: The circadian clock Period 2 gene regulates gamma interferon production of NK cells in host response to lipopolysaccharide-induced endotoxic shock. Infect Immun 74: 4750-4756, 2006.

42. Keller M, Mazuch J, Abraham U, Eom GD, Herzog ED, Volk HD, Kramer A and Maier B: A circadian clock in macrophages controls inflammatory immune responses. Proc Natl Acad Sci USA 106: 21407-21412, 2009.

43. Hashiramoto A, Yamane T, Tsumiyama K, Yoshida K, Komai K, Yamada H, Yamazaki F, Doi M, Okamura H and Shiozawa S: Mammalian clock gene Cryptochrome regulates arthritis via proinflammatory cytokine TNF-alpha. J Immunol 184: $1560-1565,2010$.

44. Yoshida K, Hashimoto T, Sakai Y and Hashiramoto A: Involvement of the circadian rhythm and inflammatory cytokines in the pathogenesis of rheumatoid arthritis. J Immunol Res 2014: 282495,2014 